\title{
Solvent Effects on the Reduction Mechanism of 9-Chloroanthracene, 3-Nitrobenzyl Chloride and 3-Chloroacetophenone
}

\author{
Henrik Jensen and Kim Daasbjerg* \\ Department of Organic Chemistry, University of Aarhus, DK-8000 Aarhus C, Denmark
}

\begin{abstract}
Jensen, H. and Daasbjerg, K., 1998. Solvent Effects on the Reduction Mechanism of 9-Chloroanthracene, 3-Nitrobenzyl Chloride and 3-Chloroacetophenone. Acta Chem. Scand. 52: 1151-1164. C Acta Chemica Scandinavica 1998.

The reduction mechanism of 9-chloroanthracene, 3-nitrobenzyl chloride and 3chloroacetophenone has been investigated in detail by means of cyclic voltammetry and controlled potential bulk electrolysis. The investigation was carried out in a number of aprotic solvents in order to elucidate the importance of solvation phenomena on the various parameters associated with the reaction mechanism, i.e., cleavage, hydrogen abstraction, protonation and dimerization rate constants as well as standard potentials. In this connection, the influence of the supporting electrolyte in terms of ion pairing and double layer effects has been considered. For the radical anions of 9-chloroanthracene and 3-nitrobenzyl chloride the logarithm of the cleavage rate constant shows a linear dependence on the Gutmann acceptor number and donor number, respectively, whereas no clearcut correlation can be observed in the case of the radical anion of 3-chloroacetophenone. The rate constant obtained for the protonation reaction between 3nitrobenzyl anion and 3-nitrobenzyl chloride is to an even higher extent influenced by the nature of the solvent. The trends in the solvent effects are discussed.
\end{abstract}

Radical anions play a central role in important electron transfer mechanisms within many chemical systems. ${ }^{1}$ Information about the lifetime of radical anions and the factors governing their reactivity towards cleavage is therefore of much interest. Some of the most important terms considered previously in this respect have been the energy of the SOMO (single occupied molecular orbital), spin density distribution, orbital symmetry, geometry, bond strength, solvent and temperature. ${ }^{2-21} \mathrm{~A}$ more quantitative approach has been presented recently by Savéant ${ }^{22,23}$ who has modelled the cleavage process as an intramolecular electron transfer. The factors governing the process are then incorporated in parameters such as solvent reorganization energy, bond dissociation energy and standard potentials.

In this paper we focus on the influence of the solvent on the reactivity of radical anions towards cleavage. Our main objective is to investigate, in further detail, the correlations normally observed between the cleavage rate and the empirical solvent parameter, the Gutmann acceptor number, and in particular whether or not they are as independent of the radical anion structure as they seem to be at first sight. ${ }^{14-20}$ An important point to emphasize in this respect is that most of the previous studies $^{14-18}$ have been based on the pulse radiolysis

\footnotetext{
* To whom correspondence should be addressed.
}

technique although many of the organic solvents employed are not well described as absorbents of radiation. In fact, a huge discrepancy of several orders of magnitude is observed in the stability of some of the radical anions investigated ${ }^{14,15}$ when compared with results obtained under electrochemical and less severe conditions. ${ }^{19,20,24}$

We chose to study the radical anions of 3-nitrobenzyl chloride and 3-chloroacetophenone as model systems in an electrochemical approach. Both compounds are characterized by the presence of charge localization groups and this could open up for some interesting solvation effects in the initial state as well as the transition state. The radical anion of 9-chloroanthracene has been included to represent a delocalized system without any significant initial state solvation effect. Although the latter compound has been studied electrochemically in some solvents previously ${ }^{19,20}$ a full investigation has been carried out herein since the mechanistic picture as well as the series of aprotic solvents used differ. The solvents tetrahydrofuran (THF), hexamethylphosphoric triamide (HMPA), 1-methyl-2-pyrrolidinone (NMP), $N, N$ dimethylformamide (DMF), acetonitrile $\left(\mathrm{CH}_{3} \mathrm{CN}\right)$, dimethyl sulfoxide (DMSO) and dichloromethane $\left(\mathrm{CH}_{2} \mathrm{Cl}_{2}\right)$, were selected because of their suitability for electrochemical measurements and because the relevant solvent parameters were available. 
The first part of the paper is devoted to a mechanistic analysis of the electrochemical reduction of the three title compounds by means of cyclic voltammetry (CV), linear sweep voltammetry (LSV) and controlled potential reductions. As will become clear later the structure of the three compounds and their radical anions makes them prone to undergo various reactions including cleavage, hydrogen abstraction, protonation and dimerization processes. In the second part, the role of ion pairing and double layer effects has been investigated, and the importance such phenomena could have on the interpretation of the data extracted in the electrochemical study are considered. Finally, the solvent effect on the various parameters associated with the reaction mechanism is discussed in the third part of the paper in relation to literature results. In particular, attention is focused on the trend in the magnitude of the cleavage rate constants obtained in the different solvents.

\section{Results and discussion}

Mechanistic analysis: 9-chloroanthracene. The electrochemical reduction of 9-chloroanthracene $(\mathrm{AnCl})$ has been described previously by a DISP1-HAT (hydrogen atom transfer) mechanism in $\mathrm{DMSO}^{25}$ and this scheme, eqns. (1)-(5), seems to be valid for most of the solvents in question in the present study.

$$
\begin{aligned}
& \mathrm{AnCl}+\mathrm{e}^{-} \leftrightharpoons \mathrm{AnCl}^{-} \\
& \mathrm{AnCl}^{-} \stackrel{k_{\mathrm{cl}}}{\longrightarrow} \mathrm{An}^{\cdot}+\mathrm{Cl}^{-} \\
& \mathrm{An}^{-}+\mathrm{AnCl}^{-} \longrightarrow \mathrm{An}^{-}+\mathrm{AnCl} \\
& \mathrm{An}^{\cdot}+\mathrm{SH}^{k_{\text {abs }}} \longrightarrow \mathrm{AnH}+\mathrm{S}^{\cdot} \\
& \mathrm{S}^{\cdot}+\mathrm{AnCl}^{-} \longrightarrow \mathrm{S}^{-}+\mathrm{AnCl}
\end{aligned}
$$

The initial heterogeneous electron transfer (1) from the electrode to 9-chloroanthracene forms the corresponding radical anion in which the carbon-halogen bond is cleaved in a relatively slow follow-up reaction (2). The easily reducible and good hydrogen atom abstracting anthryl radical thus generated may be further reduced by the radical anion of 9-chloroanthracene and/or abstract a hydrogen atom from the solvent $\mathrm{SH}$ as shown in eqns. (3) and (4). In the absence of the latter reaction the mechanism constitutes the well-known DISP1 case, in which the overall electron stoichiometry corresponds to a two-electron reduction of 9-chloroanthracene. If a solvent-derived radical $\mathbf{S}^{-}$is formed a further reduction (5) by the radical anion of 9-chloroanthracene is often possible. The voltammetric behaviour associated with such a pathway is exactly as for the DISP1 case and the cleavage rate constant may be determined by the same procedure no matter what the magnitude of the competition ratio of reactions (3) and (4).

Experimentally, a two-electron reduction wave of 9chloroanthracene followed by a smaller and reversible wave are observed at low scan rates $\left(v<0.1 \mathrm{~V} \mathrm{~s}^{-1}\right)$ in cyclic voltammetry in most solvents, i.e., THF, HMPA,
$\mathrm{CH}_{3} \mathrm{CN}, \mathrm{CH}_{2} \mathrm{Cl}_{2}$ and DMSO. The second wave is attributed to the electrode process of anthracene, $\mathrm{AnH}$, that is generated in reaction (3) after protonation of $\mathrm{An}^{-}$ and/or in reaction (4). As the scan rate is increased the first reduction becomes a one-electron reversible process and the second wave disappears concurrently. For the two solvents, NMP and DMF, the characteristics of the cyclic voltammograms differ from the above description and the mechanism cannot be fitted to DISP1 as suggested elsewhere. ${ }^{20}$ In fact, the height of the reduction wave of 9-chloroanthracene corresponds to the expected two-electron stoichiometry only when the substrate concentration is as high as $20 \mathrm{mM}$. As the substrate concentration is lowered to $1 \mathrm{mM}$ the stoichiometry decreases towards 1.3 and 1.5, respectively. This feature of the substrate dependent competition between reactions (3) and (4) now detectable points to the presence of an additional reaction in the HAT scheme not considered previously, i.e., the coupling reaction (6).

$\mathrm{S}^{\cdot}+\mathrm{AnCl}^{-} \longrightarrow \mathrm{SAnCl}^{-}$

A contribution from a reaction between a radical anion and a radical as outlined above is not unusual and it is now well documented for many similar systems. ${ }^{26.27}$ A characteristic rate constant for this reaction type is $10^{9} \mathrm{M}^{-1} \mathrm{~s}^{-1}$ and thus reaction (6) can be neglected only when the competing electron transfer reaction (5) is so exergonic that its rate is close to the diffusion-controlled limit $\left(\approx 10^{10} \mathrm{M}^{-1} \mathrm{~s}^{-1}\right)$. This is contrary to expectation since the reduction potential of the DMF derived radical is $-1.62 \mathrm{~V}$ vs. SCE in $\mathrm{DMF}^{28}$ while the standard potential of 9-chloroanthracene only is slightly lower $(-1.66 \mathrm{~V}$ vs. SCE in DMF) as measured herein.

The hydrogen abstraction rate constant $k_{\text {abs }}$ (given as a first-order rate constant) for both NMP and DMF is determined to be ca. $2 \times 10^{7} \mathrm{~s}^{-1}$ by digital simulation of the voltammetric behaviour in the two solvents as described in the Experimental part. In comparison, the corresponding value for the poorer $\mathrm{H}$-atom donor solvents DMSO and $\mathrm{CH}_{3} \mathrm{CN}$ has been estimated to $8.5 \times 10^{6}$ and $2 \times 10^{7} \mathrm{~s}^{-1}$, respectively, on the basis of product studies. ${ }^{25}$

The cleavage rate constants, $k_{\mathrm{cl}}$, for the radical anion of 9-chloroanthracene have been determined in the different solvents by the two LSV approaches described in the Experimental part. The results are summarised in Table 1 together with relevant literature values ${ }^{19,20}$ obtained primarily at low substrate concentration and on the basis of a DISP1 mechanism. The deviation from the literature results is, in general, relatively small but one solvent represents an exception, namely DMF. We have no explanation for the discrepancy being so high that it cannot be attributed to the neglect of reaction (6) in the mechanistic picture in the previous investigation, ${ }^{20}$ or to the various amounts of residual water always present in the solvent. The addition of water to a concentration of $20 \mathrm{mM}$ was found to have no influence on the cyclic voltammetric behaviour. It should also be 
Table 1. The cleavage rate constant of the radical anion of 9-chloroanthracene, $k_{\mathrm{cl}}$, and the standard potential of 9chloroanthracene, $E^{\circ}$, obtained in different solvents. The uncertainty on $k_{\mathrm{cl}}$ is estimated to be $20 \%$.

\begin{tabular}{lrrll}
\hline Solvent & $k_{\mathrm{cl}}{ }^{a}$ & \multicolumn{1}{c}{$k_{\mathrm{cl}}{ }^{b}$} & $k_{\mathrm{cl}}$ & $-E^{\circ e}$ \\
\hline $\mathrm{CH}_{3} \mathrm{CN}$ & 130 & 142 & $165^{c} 200^{d}$ & 2.140 \\
DMSO & 100 & 110 & $120^{c} 150^{d}$ & 2.090 \\
DMF & 62 & 62 & $131^{c}$ & 2.140 \\
NMP & 42 & 40 & & 2.135 \\
HMPA & 32 & 38 & $40^{c}$ & 2.180 \\
THF & 24 & 26 & $40^{d}$ & 2.210 \\
$\mathrm{CH}_{2} \mathrm{Cl}_{2}$ & 170 & 180 & $220^{d}$ & 2.220 \\
\hline
\end{tabular}

${ }^{a}$ In $\mathrm{s}^{-1}$, measured by the peak potential method in LSV at $20^{\circ} \mathrm{C}^{b} \mathrm{In} \mathrm{s}^{-1}$, measured from the catalytic efficiency in LSV at $20^{\circ} \mathrm{C}^{c}{ }^{c} \mathrm{n} \mathrm{s}^{-1}$, from Ref. 20 at $22^{\circ} \mathrm{C}^{d}{ }^{d}$ In s ${ }^{-1}$, from Ref. 19. ${ }^{e}$ In $\mathrm{V}$ vs. $\mathrm{Fc}^{+} / \mathrm{Fc}^{\prime}$.

noted that a pulse radiolytic study of 9-chloroanthracene radical anion in five aprotic solvents ${ }^{15}$ has given values of the cleavage rate constant $\left(>10^{5} \mathrm{~s}^{-1}\right)$ several orders of magnitude higher. We suspect that these results may have been affected by the occurrence of secondary reactions between the radical anion of 9-chloroanthracene and solvent-derived radiolysis products generated by the high-energy electron pulse since agreement between electrochemical and pulse radiolytic data is normally observed. ${ }^{29}$

3-Nitrobenzyl chloride. The electrochemical reduction of 3-nitrobenzyl chloride $\left(\mathrm{RCH}_{2} \mathrm{Cl}\right)$ has been described previously by a hydrogen abstraction mechanism in $\mathrm{CH}_{3} \mathrm{CN}^{30}$ and an EC mechanism in $\mathrm{DMF}^{3}$ As shown in Fig. 1 the cyclic voltammogram recorded at low scan rate is characterized by an irreversible wave followed by

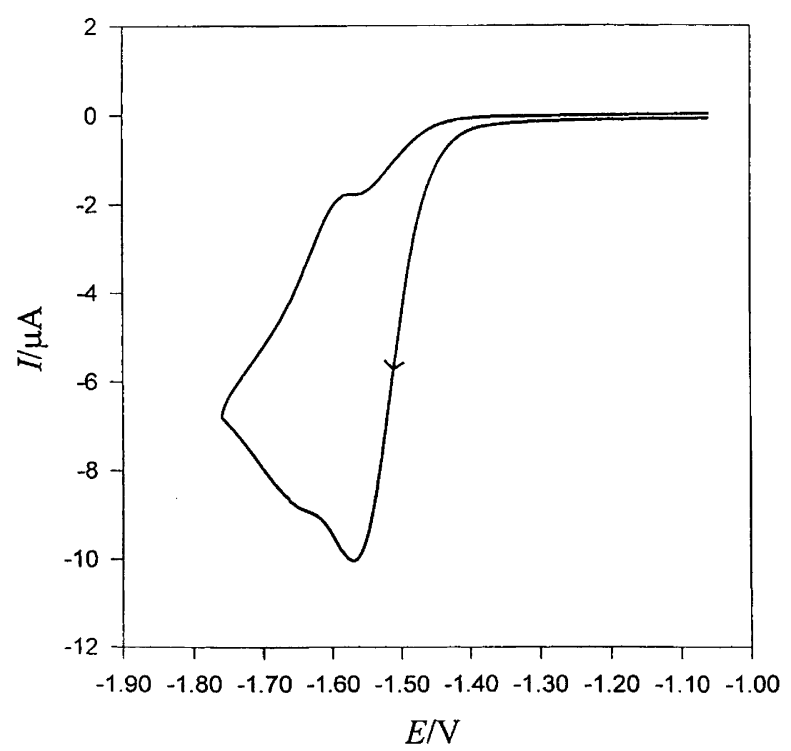

Fig. 1. Cyclic voltammogram of 3-nitrobenzyl chloride at a concentration of $2 \mathrm{mM}$ obtained at a glassy carbon electrode in $0.3 \mathrm{M} \mathrm{TBABF}{ }_{4}-\mathrm{THF}$ at a scan rate of $0.1 \mathrm{~V} \mathrm{~s}^{-1}$. The potential $E$ is measured against $\mathrm{Fc}^{+} / \mathrm{Fc}$. a smaller and reversible wave, the electron stoichiometries of which are dependent on substrate concentration as well as solvent. In general, the electron stoichiometry of the first reduction wave increases as the substrate concentration is lowered and at $2 \mathrm{mM}$ it corresponds to about 1.2 for DMF whereas it can be as high as about 1.9 for THF and $\mathrm{CH}_{2} \mathrm{Cl}_{2}$. Addition of 3-nitrotoluene to the electrochemical cell results in an increase of the second wave while the presence of chloroform enhances both waves. At scan rates of $10-20 \mathrm{~V} \mathrm{~s}^{-1}$ the second wave disappears and the first wave corresponds to a oneelectron quasi-reversible process as deduced from a comparison with the one-electron oxidation of ferrocene. The standard heterogeneous rate constant $k^{\circ}$ is determined to be $0.25 \mathrm{~cm} \mathrm{~s}^{-1}$ at a gold electrode in acetonitrile by measurement of the peak separation as a function of scan rate. ${ }^{31}$

The features described above combined with the results of the product analysis described in the Experimental part point to a different mechanism, compromising eqns. (7)-(11), from that suggested previously.

$$
\begin{aligned}
& \mathrm{RCH}_{2} \mathrm{Cl}+\mathrm{e}^{-} \rightleftharpoons \mathrm{RCH}_{2} \mathrm{Cl}^{--} \\
& \mathrm{RCH}_{2} \mathrm{Cl}^{-}-\stackrel{k_{\mathrm{cl}}}{\longrightarrow} \mathrm{RCH}_{2}{ }^{-}+\mathrm{Cl}^{-} \\
& \mathrm{RCH}_{2}{ }^{-}+\mathrm{RCH}_{2} \mathrm{Cl}^{-} \longrightarrow \mathrm{RCH}_{2}^{-}+\mathrm{RCH}_{2} \mathrm{Cl} \\
& \mathrm{RCH}_{2}{ }^{-}+\mathrm{RCH}_{2} \mathrm{Cl} \stackrel{k_{\mathrm{pr}}}{\longrightarrow} \mathrm{RCH}_{3}+\mathrm{R} \overline{\mathrm{C}} \mathrm{HCl} \\
& \mathrm{RCH}_{3}+\mathrm{e}^{-} \rightleftharpoons \mathrm{RCH}_{3} \cdot-
\end{aligned}
$$

The heterogeneous reduction process (7) is followed by cleavage reaction (8) and reduction (9) of 3-nitrobenzyl radical. Reaction (9) is expected to be fast and essentially irreversible since the standard potential of 3nitrobenzyl chloride as measured by cyclic voltammetry is $-1.06 \mathrm{~V}$ vs. $\mathrm{SCE}$ in $\mathrm{CH}_{3} \mathrm{CN}$ while the standard potential of 3-nitrobenzyl radical is $-0.65 \mathrm{~V}$ vs. SCE in $\mathrm{CH}_{3} \mathrm{CN}$ as deduced from a Hammett plot. $^{3}$ 3Nitrobenzyl anion may be protonated by 3-nitrobenzyl chloride to 3-nitrotoluene, eqn. (10), which is the origin of the second reversible wave as described by reaction (11) and the fact that the electron stoichiometry of the first reduction wave is smaller than two and dependent on the substrate concentration and solvent. The effect of chloroform on the cyclic voltammetric behaviour is ascribed to the replacement of 3-nitrobenzyl chloride by the stronger acid chloroform in the protonation reaction (10). The anion of 3-nitrobenzyl chloride produced in reaction (10) could form a carbene after expulsion of chloride but an attempt to trap the carbene with cyclohexene on a preparative scale was unsuccessful.

The cleavage and protonation rate constants, $k_{\mathrm{cl}}$ and $k_{\mathrm{pr}}$, were determined by fitting the experimental results obtained in LSV to working curves depicting the catalytic efficiency (defined as the ratio of the actual peak current, $I_{\mathrm{k}}$, and the one-electron peak current of the corresponding reversible process, $I_{\mathrm{r}}$ ) or the peak potential of the reduction wave, $E_{\mathrm{p}}$, as a function of $R T k_{\mathrm{cl}} / F v$ for different values of $c^{*} k_{\mathrm{pr}} / k_{\mathrm{cl}}$, where $c^{*}$ denotes the sub- 
strate concentration. The second set describing $E_{\mathrm{p}}$ was only slightly influenced by the magnitude of $c^{*} k_{\mathrm{pr}} / k_{\mathrm{cl}}$ and thus not well suited for the determination of $k_{\mathrm{pr}}$. In general, the experimental results fit rather well to the theoretical predictions as exemplified in the case of THF and $\mathrm{CH}_{3} \mathrm{CN}$ in Fig. 2 allowing $k_{\mathrm{cl}}$ as well as $k_{\mathrm{pr}}$ to be obtained.

The protonation rate constants and the two sets of cleavage rate constants obtained are gathered in Table 2. If the protonation reaction is very fast as observed in DMF, NMP and HMPA, i.e., $c^{*} k_{\mathrm{pr}} / k_{\mathrm{cl}}>20$, the catalytic efficiency is only slightly dependent on the protonation rate and access to $k_{\mathrm{pr}}$ is not at hand. In $\mathrm{CH}_{2} \mathrm{Cl}_{2}$, the determination of $k_{\mathrm{pr}}$ is associated with a high uncertainty since the term $c^{*} k_{\mathrm{pr}} / k_{\mathrm{cl}}$ is small $(<0.02)$ and close to the lower detection limit. The effect of possible side reactions would also be expected to be more serious for slow protonation processes. For most solvents the sets of $k_{\mathrm{cl}}$ are consistent but NMP and DMF represent exceptions with deviations of a factor of two. An attempt to fit the whole experimental cyclic voltammogram recorded in DMF to simulations was not encouraging since the theoretical curves characteristically overestimated the magnitude of the second wave of 3-nitrotoluene compared with the first wave of 3-nitrobenzyl chloride. This indicates that the mechanism proposed may not be fully adequate for these two solvents and that the correspond-

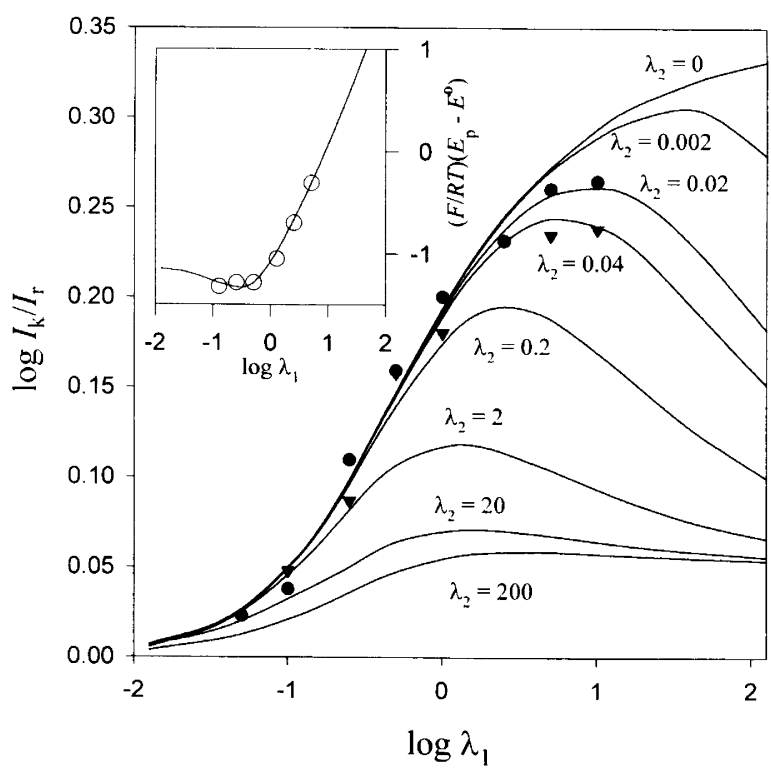

Fig. 2. Plot of the logarithm of the catalytic efficiency, $\log l_{\mathrm{k}} / I_{\mathrm{r}}$ vs. $\log \lambda_{1}\left(\lambda_{1}=R T k_{\mathrm{cl}} / F v\right)$ for 3-nitrobenzyl chloride in a concentration of $10(-)$ and $20 \mathrm{mM}(\boldsymbol{\nabla})$ in $0.3 \mathrm{M} \mathrm{TBABF}_{4}-\mathrm{THF}$. The scan rate is varied from 0.05 to 10 and 0.05 to $5 \mathrm{~V} \mathrm{~s}^{-1}$, respectively, in the two cases. The theoretical behaviour is shown by the solid curves for different values of $\lambda_{2}=c^{*} k_{\mathrm{pr}} / k_{\mathrm{cl}}$, where $c^{*}$ denotes the substrate concentration. The insert is a plot of the peak potential $E_{\mathrm{p}}$ vs. $\log \lambda_{1}$ for $10 \mathrm{mM}$ 3nitrobenzyl chloride in $0.1 \mathrm{M} \mathrm{TBABF}{ }_{4}-\mathrm{CH}_{3} \mathrm{CN}$. The scan rate is varied from 0.05 to $2 \mathrm{~V} \mathrm{~s}^{-1}$. The $\lambda_{2}$ parameter is set equal to 0.1 in the simulation of the theoretical curve shown by the solid curve.
Table 2. The cleavage rate constant of the radical anion of 3-nitrobenzyl chloride, $k_{\mathrm{cl}}$, the protonation rate constant of the reaction between 3-nitrobenzyl anion and 3-nitrobenzyl chloride, $k_{\mathrm{pr}}$, and the standard potential of 3-nitrobenzyl chloride, $E^{\circ}$, obtained in different solvents. The uncertainty on $k_{\mathrm{cl}}$ and $k_{\mathrm{pr}}$ is estimated to be 20 and $50 \%$, respectively.

\begin{tabular}{lrrrcr}
\hline Solvent & $k_{\mathrm{cl}}{ }^{a}$ & $k_{\mathrm{cl}}{ }^{b}$ & $k_{\mathrm{cl}}$ & $k_{\mathrm{pr}}{ }^{e}$ & $-E^{\circ g}$ \\
\hline $\mathrm{CH}_{3} \mathrm{CN}$ & 9 & 10 & $10^{c}$ & 100 & 1.465 \\
DMSO & 41 & 30 & & 3000 & 1.435 \\
DMF & 77 & 30 & $80^{d}$ & $>10^{5 f}$ & 1.510 \\
NMP & 88 & 34 & & $>10^{5 f}$ & 1.535 \\
HMPA & 173 & 113 & & $>10^{5}$ & 1.625 \\
THF & 25 & 21 & & 40 & 1.595 \\
$\mathrm{CH}_{2} \mathrm{Cl}_{2}$ & 4 & 5 & & $5^{f}$ & 1.545 \\
\hline
\end{tabular}

${ }^{a}$ In $\mathrm{s}^{-1}$, measured by the peak potential method in LSV at $20^{\circ} \mathrm{C}$. ${ }^{\prime}$ In s s${ }^{-1}$, measured from the catalytic efficiency in LSV at $20^{\circ} \mathrm{C}$. ${ }^{c}$ In $\mathrm{s}^{-1}$, from Ref. 32. ${ }^{d} \ln \mathrm{s}^{-1}$, from Ref. 3. ${ }^{e}$ In $\mathrm{M}^{-1} \mathrm{~s}^{-1}$, measured from the catalytic efficiency in LSV at $20{ }^{\circ} \mathrm{C}$. ${ }^{\text {T }}$ The determination is uncertain due to mechanistic complications. ${ }^{g}$ In $\mathrm{V}$ vs. $\mathrm{Fc}^{+} / \mathrm{Fc}$.

ing rate constants are subject to higher uncertainty. We believe the peak potential method provides the most reliable results since digital simulations proved the determination of $k_{\mathrm{cl}}$ to be rather insensitive not only to the magnitude of the other simulation parameters but also to changes in mechanism following the cleavage reaction.

3-Chloroacetophenone. The electrochemical reduction of 3-chloroacetophenone $(\mathrm{AcCl})$ has been described previously by an ECE mechanism in $\mathrm{DMF}^{24}$ and an EC mechanism in $\mathrm{CH}_{3} \mathrm{CN}^{32} \mathrm{~A}$ typical cyclic voltammogram obtained at low scan rate is shown in Fig. 3. It is

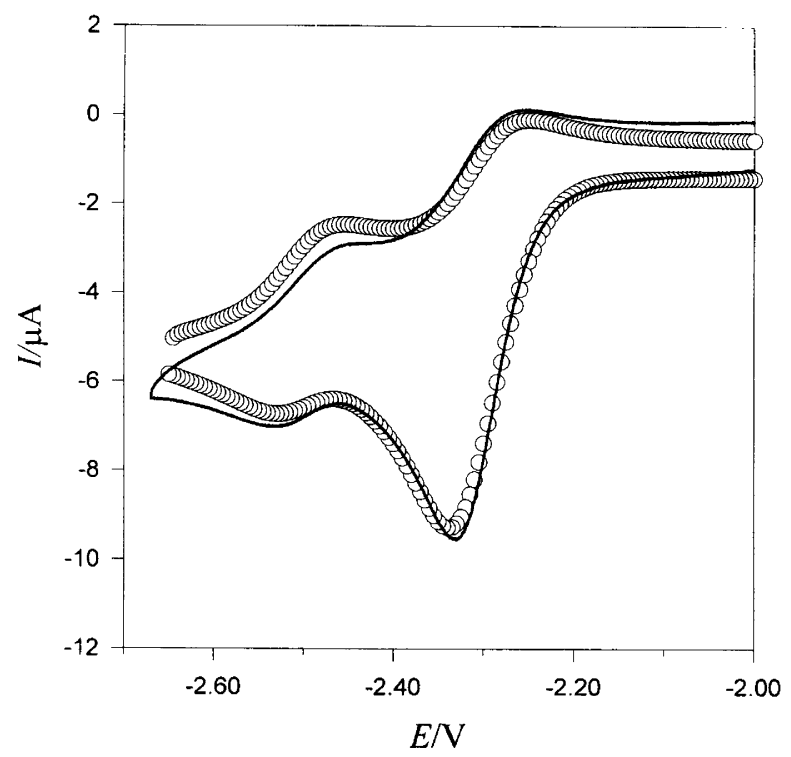

Fig. 3. Cyclic voltammogram of 3-chloroacetophenone at a concentration of $2 \mathrm{mM}$ obtained at a glassy carbon electrode in $0.3 \mathrm{M} \mathrm{TBABF}_{4}-\mathrm{THF}$ at a scan rate of $0.2 \mathrm{~V} \mathrm{~s}^{-1}$. The potential $E$ is measured against $\mathrm{Fc}^{+} / \mathrm{Fc}$. The simulated curve $(O)$ is obtained as described in the text using $k_{\mathrm{cl}}=0.6 \mathrm{~s}^{-1}$ and $2 k_{\text {dim }}=2 \times 10^{3} \mathrm{M}^{-1} \mathrm{~s}^{-1}$. 
characterized by two waves, with the second reversible wave corresponding to the reduction of acetophenone as deduced by comparison with the electrochemical behaviour of an authentic sample of this compound. On the reverse scan a small oxidation wave (not shown in Fig. 3) constituting $1-5 \%$ of the height of the 3 -chloroacetophenone reduction wave appears at a potential of about $-1.0 \mathrm{~V}$ against $\mathrm{Fc}^{+} / \mathrm{Fc}$. At higher scan rates $\left(v>5 \mathrm{~V} \mathrm{~s}^{-1}\right)$ quasi-reversibility of the first wave $\left(k^{\circ} \approx 0.1 \mathrm{~cm} \mathrm{~s}^{-1}\right.$ at a gold electrode in acetonitrile as measured from the peak separation as a function of scan rate) ${ }^{31}$ accompanied by the disappearance of the acetophenone reduction wave can be observed in all solvents. Both the ratio of anodic to cathodic current of the first wave and the relative wave height of the generated acetophenone are, in most solvents, found to be dependent on the substrate concentration. This points to the presence of a competing second-order dimerization reaction in which the small anodic peak observed on the reverse scan in cyclic voltammetry should be attributed to the dimer. In fact, the electrochemical reduction of other aromatic compounds containing carbonyl groups ${ }^{33,34}$ has provided strong evidence of such a dimerization process that should be accelerated by water. ${ }^{33,35,36}$ Actually, when water was added $(\approx 100 \mathrm{mM})$ to the solution containing 3-chloroacetophenone the reduction peak of acetophenone disappeared completely in the cyclic voltammogram and chemical reversibility of the first wave could be obtained only at a much higher scan rate.

On the basis of these results and the preparative reductions described in the Experimental part the electrochemical reduction is suggested to be described by a mixed DIM 1-HAT mechanism, eqns. (12)-(16).

$$
\begin{aligned}
& \mathrm{AcCl}+\mathrm{e}^{-} \rightleftharpoons \mathrm{AcCl}^{-} \\
& 2 \mathrm{AcCl}^{-} \stackrel{k_{\mathrm{dim}}}{\longrightarrow} \mathrm{ClAc}^{-} \mathrm{AcCl}^{2-} \\
& \mathrm{AcCl}^{-} \stackrel{k_{\mathrm{cl}}}{\longrightarrow} \mathrm{Ac}^{\cdot}+\mathrm{Cl}^{-} \\
& \mathrm{Ac}^{\cdot}+\mathrm{SH} \longrightarrow \mathrm{AcH}+\mathrm{S}^{\cdot} \\
& \mathrm{S}^{\cdot}+\mathrm{AcCl}^{-} \longrightarrow \mathrm{S}^{-}+\mathrm{AcCl}
\end{aligned}
$$

The scheme describes the competition between, on the one hand, the dimerization process (13) and, on the other hand, the cleavage reaction (14) of the radical anion followed by a fast hydrogen abstraction (15) from the solvent and reduction (16) of the thus generated solvent radical. Reaction (15) is expected to be much faster than the corresponding reaction (4) in the reduction mechanism of 9-chloroanthracene considering the very good hydrogen abstracting abilities of substituted phenyl radicals. ${ }^{25}$ The presence of a competing reduction of $\mathrm{Ac}^{-}$by $\mathrm{AcCl}^{-}$- cannot be excluded totally but this will have no influence on the cyclic voltammetric response. A coupling reaction between $\mathrm{S}^{\cdot}$ and $\mathrm{AcCl}^{-}$ corresponding to reaction (6) is unlikely owing to the higher reducing power of $\mathrm{AcCl}^{-}\left(E^{\circ}\right.$ of $\mathrm{AcCl} \approx-2.2 \mathrm{~V}$ vs. $\left.\mathrm{Fc}^{+} / \mathrm{Fc}\right)$. This should favour the electron transfer process (16) and allow it to proceed with a rate at the diffusion-controlled limit. The second wave observed in the voltammogram is attributed to the reduction of acetophenone generated in reaction (15) which may be followed by dimerization of $\mathrm{AcH}^{-}$and a cross reaction between $\mathrm{AcCl}^{-}$- and $\mathrm{AcH}^{-}$. These reactions have been omitted from the above scheme for the sake of simplicity. The dianion formed in (13) may be protonated once or twice, eventually during work-up. The small oxidation wave observed at a potential of about $-1.0 \mathrm{~V} \mathrm{vs.} \mathrm{Fc}^{+} / \mathrm{Fc}$ is most likely due to the monoanion. In principle, the dianion could be protonated by 3-chloroacetophenone but in cyclic voltammetry it was not possible to reveal any oxidation peak of the enolate ion of 3-chloroacetophenone at the expected potential. The enolate ion could be generated independently in DMSO by reacting 3chloroacetophenone with dimsyl and its peak potential was at $-0.5 \mathrm{~V}$ vs. $\mathrm{Fc}^{+} / \mathrm{Fc}$ using a scan rate of $1 \mathrm{~V} \mathrm{~s}^{-1}$ and a gold electrode.

The cleavage rate constant, $k_{\mathrm{cl}}$, and the rate constant of dimerization, $2 k_{\mathrm{dim}}$, of 3-chloroacetophenone radical anion were determined by fitting the experimental cyclic voltammograms obtained at different scan rates and substrate concentrations to digitally simulated curves. An example of a fit is shown in Fig. 3 and while the first wave is described well theoretically, the second wave of acetophenone deviates somewhat. The fit to the second wave may be improved by introducing new processes involving the radical anion of acetophenone in addition to the dimerization and cross reactions. However, since reproducible values of $k_{\mathrm{cl}}$ and $2 k_{\mathrm{dim}}$ could be obtained just by optimizing the fit to the first cyclic voltammetric wave for the different substrate concentrations and scan rates employed, such reactions were not considered in greater detail.

The values of the cleavage rates measured are gathered in Table 3 together with the few electrochemical values available in literature. ${ }^{24,32}$ Our values are appreciably lower presumably due to the differences in the mechanistic description. A pulse radiolytic study of 3-chloroacetophenone radical anion in five aprotic solvents ${ }^{14}$ has given cleavage rate constants higher than $10^{5} \mathrm{~s}^{-1}$, but we suspect that such a discrepancy, as already emphasized

Table 3. The cleavage rate constant of the radical anion of 3-chloroacetophenone, $k_{\mathrm{cl}}$, the dimerization rate constant of the radical anion of 3 -chloroacetophenone, $2 k_{\text {dim }}$, and the standard potential of 3-chloroacetophenone, $E^{\circ}$, obtained in different solvents. The uncertainty on $k_{\mathrm{cl}}$ and $2 k_{\mathrm{dim}}$ is estimated to be 20 and $50 \%$, respectively.

\begin{tabular}{lcccc}
\hline Solvent & $k_{\mathrm{cl}}{ }^{a}$ & $k_{\mathrm{cl}}$ & $2 k_{\mathrm{dim}}{ }^{d}$ & $-E^{\circ e}$ \\
\hline $\mathrm{CH}_{3} \mathrm{CN}$ & 1.3 & $15^{b}$ & 4000 & 2.235 \\
DMSO & 2.2 & & $<500$ & 2.190 \\
DMF & 1.9 & $5^{c}$ & 2000 & 2.240 \\
NMP & 3.5 & & $<700$ & 2.260 \\
THF & 0.6 & & 2000 & 2.320 \\
\hline
\end{tabular}

${ }^{a}$ In $\mathrm{s}^{-1}$, measured by $\mathrm{CV}$ at $20^{\circ} \mathrm{C}$. ${ }^{b} \mathrm{In} \mathrm{s}^{-1}$, from Ref. 32. ${ }^{c} \mathrm{In}$ $\mathrm{s}^{-1}$, from Ref. 24. ${ }^{d} \operatorname{In~} \mathrm{M}^{-1} \mathrm{~s}^{-1}$, measured by $\mathrm{CV}$ at $20^{\circ} \mathrm{C} .{ }^{\theta} \mathrm{In}$ $\mathrm{V}$ vs. $\mathrm{Fc}^{+} / \mathrm{Fc}$. 
in the case of the radical anion of 9-chloroanthracene, may be attributed to experimental limitations in the pulse radiolysis technique when applied to relatively slow reactions.

Ion pairing and adsorption effects. If ion pairing occurs between the radical anions in question and tetrabutylammonium ions from the supporting electrolyte in any of the solvents employed it would be of major importance in the interpretation of the data obtained. In particular, such an interaction should be considered for the localized radical anions of 3-nitrobenzyl chloride and 3-chloroacetophenone in non-polar solvents like THF and $\mathrm{CH}_{2} \mathrm{Cl}_{2}$. Previous electrochemical studies have focused on more polar solvents, in particular DMF, and ion pairing between tetrabutylammonium ions and radical anions of nitrobenzene, ${ }^{37}$ nitromesitylene ${ }^{38,39}$ and fullerenes ${ }^{40,41}$ has been suggested. Other investigations ${ }^{42,43}$ including an early EPR study ${ }^{42}$ on the radical anion of nitrobenzene in the presence and absence of tetraethylammonium ions in DMF, have not supported such a conclusion.

Because the electrochemical behaviour of the title compounds was complicated by the relatively fast follow-up reactions, the radical anions of 1,4-benzoquinone, nitrobenzene, phenazine, anthracene and acetophenone were selected as model compounds in this part of the study. The choice of the five substrates covering a potential range of more than $1.5 \mathrm{~V}$ provided us at the same time with the possibility of studying an eventual potential dependence of the effects observed. In particular, a comparison of the behaviour of the radical anions of nitrobenzene and phenazine was of interest considering their almost equal standard potentials, yet different degrees of charge delocalization.

In principle, the radical anion-cation association constant can be obtained electrochemically by measuring the shift in the standard potential of the substrate as a function of the cation concentration. ${ }^{44}$ The substrate concentration was therefore kept constant at $2 \mathrm{mM}$ while the concentration of the supporting electrolyte was varied from 0.02 to $0.43 \mathrm{M}$ in DMF, NMP and $\mathrm{CH}_{3} \mathrm{CN}$ and from 0.3 to $0.83 \mathrm{M}$ and 0.1 to $0.59 \mathrm{M}$ in THF and $\mathrm{CH}_{2} \mathrm{Cl}_{2}$, respectively. For all solvents a positive shift of the standard potential related linearly to the logarithm

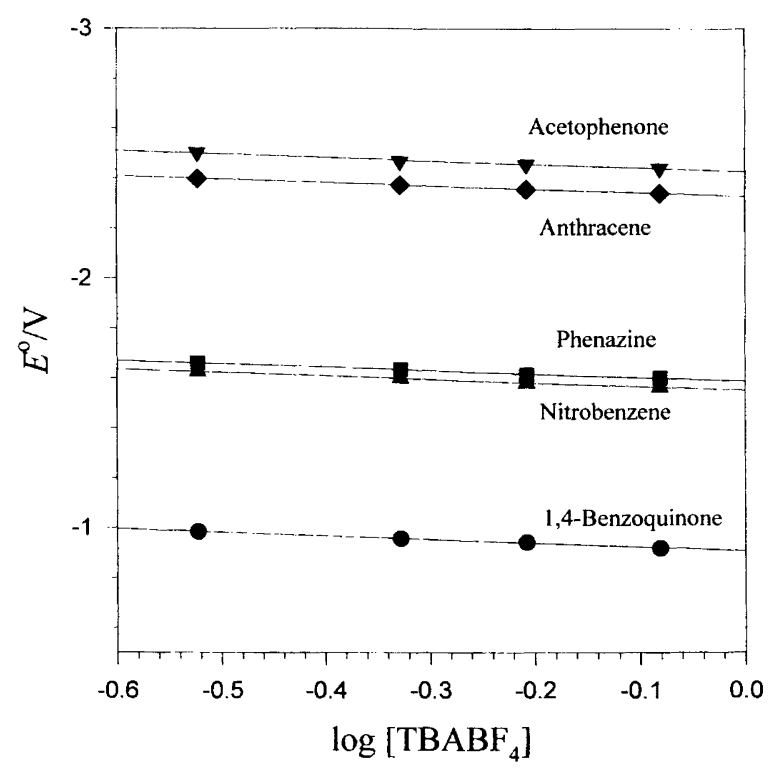

Fig. 4. Plot of the standard potential $E^{\circ}$ vs. $\log \left[T B A B F_{4}\right]$ for $2 \mathrm{mM}$ solutions of 1,4-benzoquinone, nitrobenzene, phenazine, anthracene and acetophenone in THF. The standard potential $E^{\circ}$ is measured against $\mathrm{Fc}^{+/} \mathrm{Fc}$.

of the supporting electrolyte concentration could be observed. Figure 4 shows the plot of $E^{\circ}$ vs. $\log \left[\mathrm{TBABF}_{4}\right]$ obtained for THF and Table 4 lists the magnitudes of all the slopes for the different solvents. In general, the slopes are found to be independent of the nature of the radical anion and electrode material (gold or glassy carbon) but influenced by the polarity of the solvent.

First of all it should be noted that the shift observed in potential cannot be attributed to changes in liquid junction potential, since all standard potentials were measured against the ferrocenium/ferrocene reference couple. Also it does not seem likely that the variation in $E^{\circ}$ for any of the solvents, including the non-polar THF and $\mathrm{CH}_{2} \mathrm{Cl}_{2}$, can be explained by ion pairing phenomena because different behaviour of the radical anions with localized and delocalized charges would then be expected. Moreover, if ion pairing occurred and the association constant, $K$, was smaller than $50 \mathrm{M}^{-1}$, a significant deviation from linearity between $E^{\circ}$ and $\log \left[\mathrm{TBABF}_{4}\right]$ should be observable as predicted by the theoretical expression for the potential shift, $R T \ln (1+K$

Table 4. The magnitude of the slopes of $E^{\circ}$ vs. $\log \left[\mathrm{TBABF}_{4}\right]$ plots obtained for five substrates in five different solvents. The standard potential (in $\mathrm{V}$ ) was measured at a gold electrode, unless otherwise noted. The regression coefficient was generally greater than 0.97 .

\begin{tabular}{llllll}
\hline & 1,4-Benzoquinone & Nitrobenzene & Phenazine & Anthracene & Acetophenone \\
\hline $\mathrm{CH}_{3} \mathrm{CN}$ & 0.037 & 0.043 & 0.039 & 0.046 & 0.038 \\
$\mathrm{CH}_{3} \mathrm{CN}^{\mathrm{a}}$ & 0.036 & 0.039 & 0.038 & 0.046 & 0.037 \\
$\mathrm{DMF}$ & 0.032 & 0.039 & 0.035 & 0.039 & 0.035 \\
$\mathrm{NMP}$ & 0.048 & 0.055 & 0.039 & 0.041 & 0.054 \\
$\mathrm{THF}$ & 0.15 & 0.14 & 0.14 & 0.14 & 0.14 \\
$\mathrm{CH}_{2} \mathrm{Cl}_{2}$ & 0.13 & 0.11 & 0.13 & $b$ & $b$ \\
\hline
\end{tabular}

${ }^{a}$ Measured with a glassy carbon electrode. ${ }^{b}$ Not possible to obtain due to reaction of the radical anion with the solvent. 
$\left.\left[\mathrm{TBABF}_{4}\right]\right) / F^{45}$ Note that this equation is based on the assumption that the equilibrium is established rapidly and that the complex consists of two ions

An important point to consider in the search for an explanation of the results is the constitution of the double layer and the presence of specific adsorption phenomena. ${ }^{46-48}$ If the supporting electrolyte is adsorbed specifically at the electrode surface, the oxidation and reduction potentials of the compound under investigation are expected to be affected by the concentration of the supporting electrolyte according to the Esin-Marcov equation. ${ }^{31,49,50}$ This equation predicts the electrode potential to vary linearly with the logarithm of the supporting electrolyte concentration or rather the activity of the cations or anions, such that the potential may be shifted in a positive or negative direction. The experimental results pertaining to the linear $E^{\circ}$ vs. log $\left[\mathrm{TBABF}_{4}\right]$ plots may therefore be explained by an EsinMarcov effect in terms of specific adsorption of tetrabutylammonium ions at the electrode surface at the potentials characterizing the reduction of the substrates. A contribution from specific adsorption of the tetrafluoroborate ions at the potentials of the $\mathrm{Fc}^{+} / \mathrm{Fc}$ reference system is also possible. Since the slopes reflect the relative degree of adsorption they show no significant dependence on the magnitude of the standard potential. They do, however, depend very much on the nature of the solvent, being higher in the non-polar solvents THF and $\mathrm{CH}_{2} \mathrm{Cl}_{2}$ with a relative permittivity close to $8 \mathrm{com}$ pared with NMP, $\mathrm{CH}_{3} \mathrm{CN}$ and DMF, which have values in the range $32-36.7$. This behaviour can be attributed to the fact that the degree of adsorption is governed mainly by two terms both influenced by the polarity of the solvent, namely the electrostatic interaction between the electrode and the adsorbing ion and the ability of the solvent to stabilize the ion.

In connection with this discussion the change in solvent polarity induced by the varying concentrations of supporting electrolyte should also be considered. In order to check whether this could play an important role at all in the present investigation the cleavage rate constant of the three title compounds was measured at various concentrations of the supporting electrolyte: $0.3,0.6$ and $0.9 \mathrm{M}$ in THF. Within experimental error the same value of $k_{\mathrm{cl}}$ was found in each case. The fact that three radical anions with different degrees of charge localization behave independently of the supporting electrolyte concentration supports the view that polarity changes and ion pairing effects due to the presence of the electrolyte are of minor importance in the interpretation of the data obtained.

Solvent effects. In this part the influence of the solvent on the cleavage rate constant, $k_{\mathrm{cl}}$, for the three radical anions in question and the protonation rate constant, $k_{\mathrm{pr}}$, for the reaction between 3-nitrobenzyl anion and 3nitrobenzyl chloride is analysed and discussed in relation to results already available in the literature. The rate constant of dimerization, $2 k_{\mathrm{dim}}$, obtained for 3-chloroacetophenone radical anion is influenced too much by the amount of residual water in the different solvents to allow an interpretation of these specific data. The rate constants of interest are gathered in Tables 1-3 and relevant solvent parameters originating from Refs. 51-53 are collected in Table 5.

9-Chloroanthracene. As regards the radical anion of 9chloroanthracene the cleavage rate constants obtained in the different solvents correlate well with the electrophilic properties of the solvents whether they are described by the Gutmann acceptor number, ${ }^{51}$ the Dimroth-Reichardt polarity parameter ${ }^{54,55}$ or the Fawcett acidity scale. ${ }^{56}$ These relationships are based on the assumption that the characteristics of the electrolyte/solvent mixture can be approximated by those of the pure solvent. The best correlation is obtained using the Gutmann acceptor number as shown in Fig. 5, which is even slightly better than reported previously. ${ }^{19,20}$ However, direct compar-

Table 5. The Gutmann acceptor number, AN, the Gutmann donor number, DN, the $\pi^{*}$ parameter, the Gibbs energy of transfer of the chloride ion from DMSO, $\Delta_{\mathrm{tr}} G_{\mathrm{Cl}^{-}}$, and the Gibbs energy of transfer of the proton from DMSO, $\Delta_{\mathrm{tr}} G_{\mathrm{H}^{+}}$, for different solvents.

\begin{tabular}{lccccc}
\hline Solvent & $\mathrm{AN}^{a}$ & $\mathrm{DN}^{a}$ & $\pi^{* b}$ & $\Delta_{\mathrm{tr}} G_{\mathrm{Cl}^{-}}{ }^{c}$ & $\Delta_{\mathrm{tr}} G_{\mathrm{H}^{+}}{ }^{c}$ \\
\hline $\mathrm{CH}_{3} \mathrm{CN}$ & 18.9 & 14.1 & 0.760 & 1.8 & 65.8 \\
DMSO & 19.3 & 29.8 & 1.000 & 0.0 & 0.0 \\
DMF & 16.0 & 26.6 & 0.875 & 8.0 & 1.4 \\
NMP & 13.3 & 27.3 & 0.921 & 10.7 & -5.6 \\
HMPA & 10.6 & 38.8 & 0.871 & 17.7 & 59.4 \\
THF & 8.0 & 20.0 & 0.576 & & \\
$\mathrm{CH}_{2} \mathrm{Cl}_{2}$ & 20.4 & 1 & 0.802 & $17.7^{d}$ & \\
\hline
\end{tabular}

${ }^{a}$ From Ref. 51. ${ }^{b}$ From Ref. 52. ${ }^{c}$ In kJ mol ${ }^{-1}$, from Ref. 53,

${ }^{d}$ Assumed to be the same as for 1,1-dichloroethane.

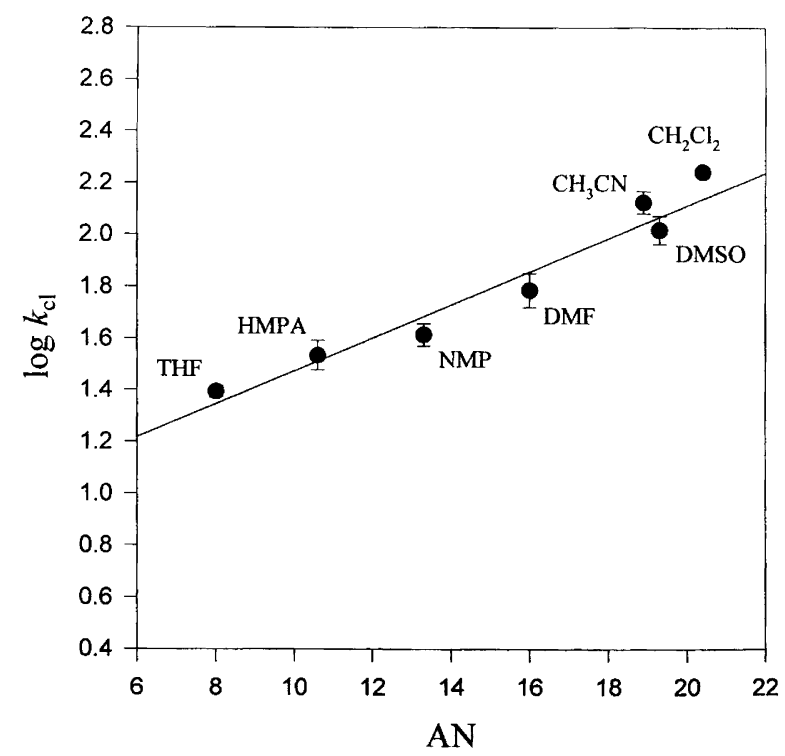

Fig. 5. Plot of $\log k_{\mathrm{cl}}$ vs. AN for the radical anion of 9-chloroanthracene. 
ison of the results from these electrochemical studies is not that meaningful considering that the mechanistic description as well as the choices of solvent differ. The correlation with the acceptor number observed in the pulse radiolytic study of 9-chloroanthracene ${ }^{15}$ is probably affected strongly by the experimental procedure employed as discussed previously.

The delocalized radical anion of 9-chloroanthracene is expected to be relatively weakly solvated and the finding of a correlation between $\log k_{\mathrm{cl}}$ and $\mathrm{AN}$ may therefore be interpreted in terms of a relatively strong interaction between the electrophilic part of the solvent molecules and the developing chloride ion in the transition state. Overall, medium effects seem to be of minor importance for the correlation. This conclusion is also in line with the observation mentioned earlier that a change in the polarity of the electrolyte/solvent mixture caused by an increase in the concentration of the supporting electrolyte has no appreciable influence on the magnitude of $k_{\mathrm{cl}}$.

3-Nitrobenzyl chloride. The solvation phenomena of the radical anion of 3-nitrobenzyl chloride are very different from those of all previous systems investigated. The cleavage rate constants show a scattered correlation with the Gutmann acceptor number only if THF is disregarded (Fig. 6). This behaviour of THF cannot be ascribed to ion pairing effects or some sort of artefact, since a similar deviation was not observed for 9-chloroanthracene. In fact, Figure 7 shows that $\log k_{\mathrm{cl}}$ correlates surprisingly well with the nucleophilic properties of the solvents as described by the Gutmann donor number. To our knowledge no other examples of such a correlation have been reported previously. Obviously, the major solvation features would be imagined to be associated with the nitro group having a localized charge in the initial state and the developing chloride ion in the

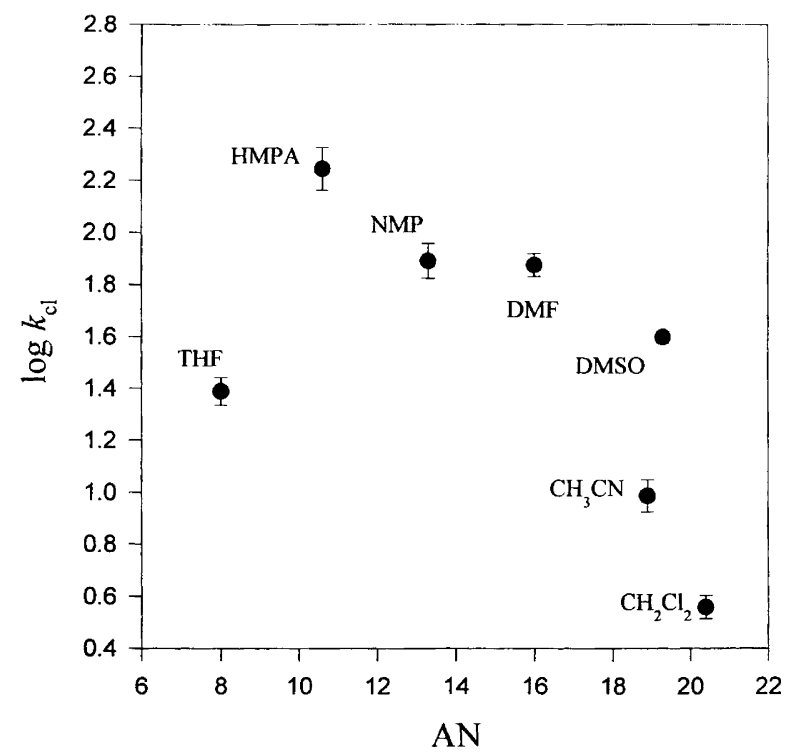

Fig. 6. Plot of $\log k_{\mathrm{cl}}$ vs. AN for the radical anion of 3-nitrobenzyl chloride.

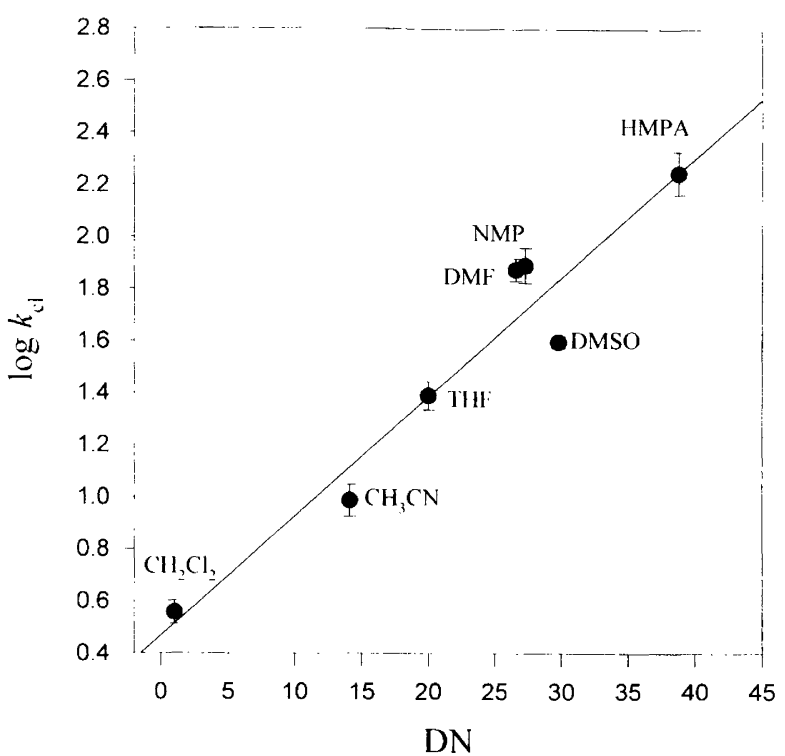

Fig. 7. Plot of $\log k_{\mathrm{cl}}$ vs. DN for the radical anion of 3-nitrobenzyl chloride.

transition state but actually these effects might counterbalance each other resulting in the overall weak sensitivity of $\log k_{\mathrm{cl}}$ towards $\mathrm{AN}$. The correlation observed with DN might then be associated with solvent assistance in the cleavage of the carbon-chlorine bond in terms of an interaction between the nucleophilic part of the solvent molecules and the primary carbon atom in the radical anion. The nucleophilic solvents may also have a stabilizing effect on the evolving electrophilic 3-nitrobenzyl radical in the transition state.

The protonation rate constants for the reaction between 3-nitrobenzyl anion and 3-nitrobenzyl chloride shown in Table 2 deserve comment. Although the determination of these rate constants is associated with high uncertainty, they are clearly even more affected than $k_{\mathrm{cl}}$ by the nature of the solvent. The development in $k_{\mathrm{pr}}$ seems to be related to the trend given by the donor numbers or the $\Delta_{\mathrm{tr}} G_{\mathrm{H}^{+}}$values in Table 5. $\dagger$ This behaviour may be explained by a strong solvent effect on the transition state in which the partially transferred proton can be stabilized by nucleophilic solvents. The initial state, on the other hand, is relatively unaffected by the solvent owing to the non-polar nature of the $\mathrm{C}-\mathrm{H}$ bond. The behaviour observed for 3-nitrobenzyl chloride, a carbon acid, is exactly the opposite of that reported for different oxygen acids in DMSO, DMF and $\mathrm{CH}_{3} \mathrm{CN}^{58}$ in which an initial state solvent effect in terms of hydrogen bonding between the polarized $\mathrm{O}-\mathrm{H}$ bond and the solvent seems to play the major role.

$\dagger$ The value of $\Delta_{\mathrm{tr}} G_{\mathrm{H}^{+}}$tabulated for HMPA in Ref. 53 is very high and seems to be overestimated. It is not reflected as it ought to be in appreciably higher $\mathrm{p} K_{\mathrm{a}} \mathrm{s}$ of acids in HMPA compared with DMF or DMSO ${ }^{57}$ and neither is similar behaviour observed for the corresponding $\Delta_{\mathrm{tr}} G_{\mathrm{Na}}+$ values. $^{53}$ 
3-Chloroacetophenone. In relation to the results obtained above the solvation effect on the radical anion of 3chloroacetophenone with a localized charge is of much interest since it has no possibility of the kind of solvent assistance in the cleavage process as does the radical anion of 3-nitrobenzyl chloride. One would therefore not expect clear-cut correlations with either $\mathrm{AN}$ or DN and this is indeed confirmed by the plots shown in Figs. 8 and 9. The correlation with $\mathrm{AN}$ reported in Ref. 14 on the basis of pulse radiolysis experiments could thus not be confirmed owing to the enormous discrepancies in the $k_{\mathrm{cl}}$ values obtained by the two methods. A significant feature of our results is related to the lower cleavage rate constant obtained in THF compared with the other

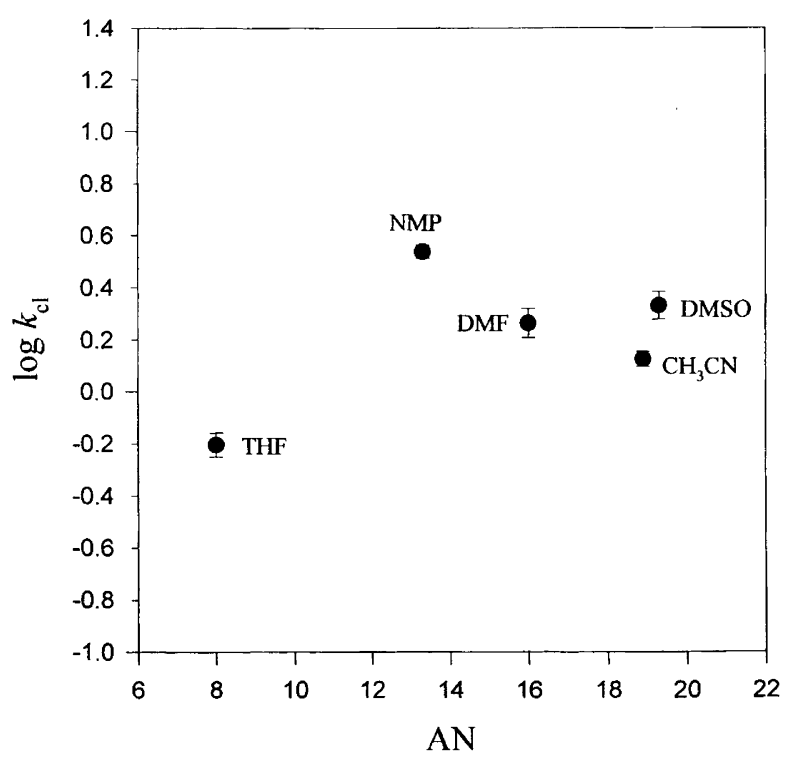

Fig. 8. Plot of $\log k_{\mathrm{cl}}$ vs. AN for the radical anion of 3-chloroacetophenone.

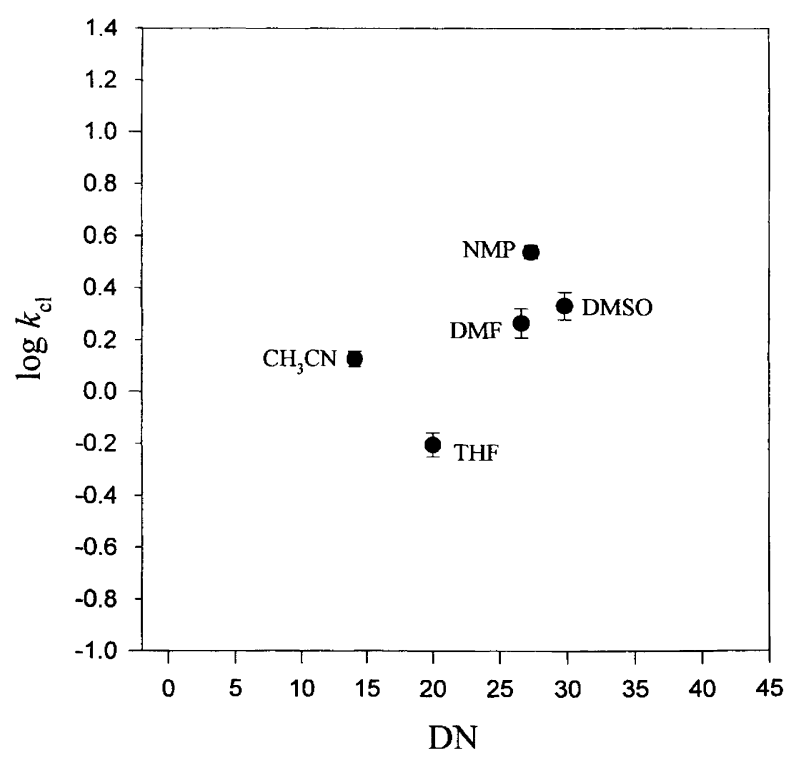

Fig. 9. Plot of $\log k_{\mathrm{cl}}$ vs. DN for the radical anion of 3-chloroacetophenone. solvents. Formally, the development in $\log k_{\mathrm{cl}}$ vs. AN obtained in Fig. 8 might be interpreted in terms of a change from a dominant transition state solvent effect at low acceptor number to a dominant initial state solvent effect at higher number. Interestingly, there seems to be a certain correlation between $\log k_{\mathrm{cl}}$ and the $\pi^{*}$ solvent parameter, which to a higher extent incorporates medium effects. The best linear fit is shown in Fig. 10. However, it should be emphasized that the correlation is based on a limited number of data and it may therefore be fortuitous. For the same reason any attempt to carry out a multi-parameter fit to two or more solvent parameters has been omitted.

Electron transfer model. Recently, Savéant ${ }^{22,23}$ has developed a theory for the cleavage reaction of radical anions, generally denoted $\mathrm{RX}^{-}{ }^{-}$, by modelling it as an intramolecular electron transfer. This theory may be invoked in a qualitative interpretation of the data pertaining to $k_{\mathrm{cl}}$, at least in the cases of 9-chloroanthracene and 3-nitrobenzyl chloride, where empirical correlations with $\mathrm{AN}$ and $\mathrm{DN}$ can be observed. The theoretical free energy relationship for the cleavage process is given below in eqns. (17) and (18).

$$
\begin{aligned}
& \Delta G_{\mathrm{RX}^{-}}^{\ddagger} \rightarrow \mathrm{R}^{\cdot}+\mathrm{X}^{-}=\Delta G_{\mathrm{O}, \mathrm{RX}^{-} \rightarrow \mathrm{R}^{\cdot}+\mathrm{X}^{-}}^{\ddagger}
\end{aligned}
$$

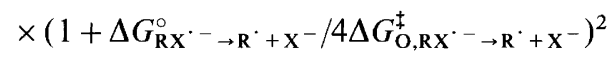

$$
\begin{aligned}
& \Delta G_{\mathrm{RX}^{\cdot-} \rightarrow \mathrm{R}^{\cdot}+\mathrm{X}^{-}}^{\circ}=D_{\mathrm{RX}}+F E_{\mathrm{RX} / \mathrm{RX}^{\cdot-}}^{\circ}-F E_{\mathrm{X}^{\cdot} / \mathrm{X}^{-}}^{\circ}
\end{aligned}
$$

In this equation, $\Delta G_{\mathrm{RX}^{-}-\rightarrow \mathrm{R}^{-}+\mathrm{X}^{-}}^{\ddagger}$ denotes the activa-

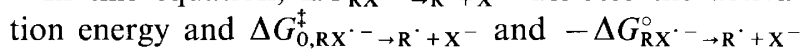
are the intrinsic barrier and driving force associated with the cleavage process. One of the most prominent terms

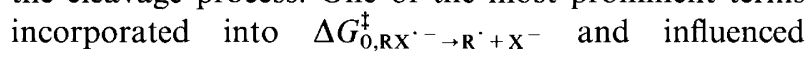

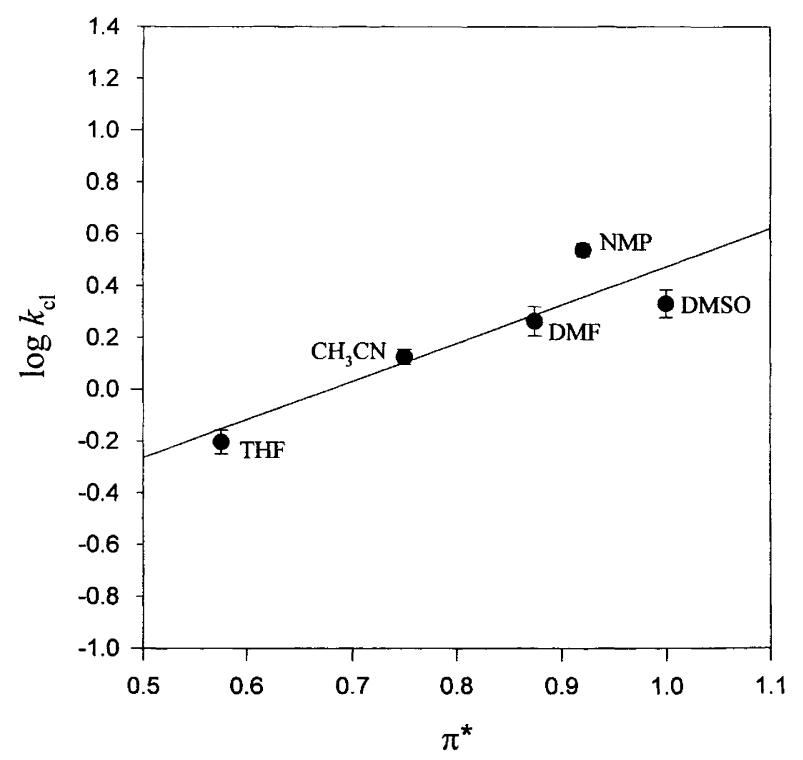

Fig. 10. Plot of $\log k_{\mathrm{cl}}$ vs. $\pi^{*}$ for the radical anion of 3-chloroacetophenone. 
strongly by solvent changes, is the solvent reorganization

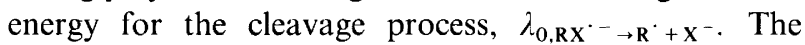
driving force can be expressed as shown in eqn. (18) when the contribution from molar entropies is neglected. The main factors governing the process are then the bond dissociation energy of the parent compound, $D_{\mathrm{RX}}$, the standard potential of $\mathrm{RX}, E_{\mathrm{RX} / \mathrm{RX}^{--}}^{\circ}$, the standard

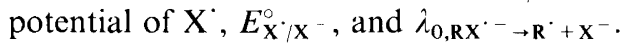

The two parameters most influential with respect to the description of solvation effects for 9-chloroanthracene radical anion are without doubt $E_{\mathbf{X}^{\prime} / \mathbf{X}^{-}}^{\circ}$ and $\lambda_{0, \mathbf{R X}} \cdots \rightarrow \mathbf{R}^{\cdot}+\mathbf{X}^{-}$. The bond dissociation energy $D_{\mathbf{R X}}$ is expected to be largely solvent independent and the standard potential $E_{\mathbf{R X} / \mathbf{R X}^{-}}^{\circ}$ will certainly be less influenced than $E_{\mathbf{X}^{*} / \mathbf{X}^{-}}^{\circ}$ by a change of solvent because of the delocalized charge in the radical anion of 9-chloroanthracene. $\S$ The importance of the $E_{\mathbf{X} / \mathbf{X}^{\circ}}^{\circ}$ - term on the cleavage rate of the radical anion of 9-chloroanthracene has been emphasized in a recent investigation, in which a small rise in $k_{\mathrm{cl}}$ as a function of the water content in $\mathrm{CH}_{3} \mathrm{CN}^{21}$ could be explained by an increase in $E_{\mathbf{X}^{*} / \mathbf{x}^{-}}^{\circ}$. In the present study a correlation between $\log k_{\mathrm{cl}}$ and the Gibbs energy of transfer of the chloride ion from a fixed solvent (chosen in this paper to be DMSO) to the other solvents, $\Delta_{\mathrm{tr}} G_{\mathrm{Cl}^{-}}$, should therefore be considered as a possibility. As may be deduced from Tables 1 and 5 such a relationship is not obvious. The solvent, $\mathrm{CH}_{2} \mathrm{Cl}_{2}$, presents a striking deviation with high values of both $k_{\mathrm{cl}}$ and $\Delta_{\mathrm{tr}} G_{\mathrm{Cl}^{-}}$. The high $\Delta_{\mathrm{tr}} G_{\mathrm{Cl}^{-}}$value can without doubt be ascribed to a medium effect due to the low dielectric constant of $\mathrm{CH}_{2} \mathrm{Cl}_{2}$, a term that is not incorporated into the Gutmann acceptor number. This deviation also suggests that $\lambda_{0, \mathrm{RX}^{-} \rightarrow \mathrm{R}^{-}+\mathrm{X}^{-}}$must be correlated strongly with $\mathrm{AN}$ if the experimental results are to be explained.

The correlation between $\log k_{\mathrm{cl}}$ and DN observed for 3-nitrobenzyl chloride is most likely due to a donor number dependent variation in $\lambda_{0, \mathbf{R X}^{-} \rightarrow \mathrm{R}^{-}+\mathrm{X}^{-}}$, while the term $E_{\mathbf{R X} / \mathbf{R X}}^{\circ}{ }^{\cdot-}-E_{\mathbf{X}^{\prime} / \mathbf{X}^{-}}^{\circ}$ is suggested to be relatively constant for the different solvents considered. This is supported by the finding of largely the same trend in the values of $E_{\mathrm{RX} / \mathrm{RX}^{-}}^{\circ}$ and $-\Delta_{\mathrm{tr}} G_{\mathrm{Cl}^{-}} / F$ given in Tables 2 and 5. Both sets of data show a correlation, although somewhat scattered, with the Gutmann acceptor number.

\section{Conclusions}

The reduction mechanism of 9-chloroanthracene, 3-nitrobenzyl chloride and 3-chloroacetophenone in several aprotic solvents has been investigated and clarified. Values of cleavage, hydrogen abstraction, protonation

$\S$ This is confirmed by the trend in the values of $E_{\mathrm{R} \times / \mathbf{R X}^{-}}^{\circ}$ and $-\Delta_{\mathrm{tr}} G_{\mathrm{Cl}^{-}} / F$ given in Tables 1 and 5 although one should be aware that the standard potentials obtained in the electrochemical experiments are influenced by the constitution of the double layer as discussed in the section on ion pairing and adsorption effects. The values of $E_{\mathrm{RX} / \mathrm{RX}}^{\circ}-$ may also incorporate small differences in the solvation features of the $\mathrm{Fc}^{+} / \mathrm{Fc}$ reference system. and dimerization rate constants as well as standard potentials have been obtained.

The rate constant of cleavage, $k_{\mathrm{cl}}$, for the radical anions of 9-chloroanthracene, 3-nitrobenzyl chloride and 3-chloroacetophenone may be influenced by the electrophilic and the nucleophilic properties of the solvent depending on the specific structure of the radical anion. Previous observations of correlations between $\log k_{\mathrm{cl}}$ and the Gutmann acceptor number based on pulse radiolysis experiments ${ }^{14.15}$ could not be confirmed in the present study and they do not seem to be a general feature unless the charge is highly delocalized as in the radical anion of 9-chloroanthracene. In this particular case the behaviour can be ascribed to a transition state solvent effect in which the ability of the solvent to stabilize the chloride ion is related to its electrophilic properties. The radical anion of 3-nitrobenzyl chloride is characterized by a localized charge as well as a primary carbon bonded to the chlorine atom, and $\log k_{\mathrm{cl}}$ now shows a linear dependence on the Gutmann donor number. This development is suggested to be governed by assistance in the cleavage of the radical anion by the nucleophilic part of the solvent molecules and by stabilization of the electrophilic 3-nitrobenzyl radical that evolves in the transition state. For the localized radical anion of 3-chloroacetophenone the same sort of solvent assistance in the cleavage process is not possible and no clear-cut correlation with either the Gutmann acceptor number or donor number exists. In this case, the best linear fit is obtained against $\pi^{*}$. The finding of any simple correlation with a single solvent parameter for a given radical anion is thus very much related to the specific structural features and is based on a delicate balance between the solvation features of the initial state and transition state.

The hydrogen abstraction rate constant for the reaction between the anthryl radical and the solvents DMF and NMP is determined to be ca. $2 \times 10^{7} \mathrm{~s}^{-1}$. The rate constant of the protonation reaction between 3-nitrobenzyl anion and 3-nitrobenzyl chloride, a weak carbon acid, generally increases as a function of the donor number of the solvent due to a transition state solvent effect. Finally, the variation observed in the standard potentials as a function of supporting electrolyte concentration is interpreted as being caused by specific adsorption of the electrolyte at the electrode surface in the different solvents rather than by ion pairing.

\section{Experimental}

Materials. 9-Chloroanthracene, 3-nitrobenzyl chloride, 3chloroacetophenone, 3-nitrotoluene, ferrocene, 1,4benzoquinone, nitrobenzene, phenazine, anthracene, acetophenone and cyclohexene were obtained commercially and used as received. The supporting electrolyte, tetrabutylammonium tetrafluoroborate $\left(\mathrm{TBABF}_{4}\right)$, was prepared and purified by standard procedures. $N, N$ Dimethylformamide (DMF), 1-methyl-2-pyrrolidinone (NMP) and hexamethylphosphoric triamide (HMPA) 
were dried before use by running the solvent through a column of freshly activated alumina. Note that HMPA is a cancer suspect agent and should be handled with extreme caution. Dimethyl sulfoxide (DMSO) was purchased from Aldrich in a sealed bottle and transferred to the cell with a syringe in order to avoid contact with moisture and air. Tetrahydrofuran (THF) was distilled under nitrogen from a solution containing sodium and benzophenone. Acetonitrile $\left(\mathrm{CH}_{3} \mathrm{CN}\right)$ and dichloromethane $\left(\mathrm{CH}_{2} \mathrm{Cl}_{2}\right)$ were distilled and dried through a column of freshly activated alumina.

Apparatus. ${ }^{1} \mathrm{H}$ NMR and ${ }^{13} \mathrm{C}$ NMR spectra were recorded with a Varian Gemini $200 \mathrm{MHz}$ spectrometer. GC-MS analysis was performed with a Hewlett Packard 5890 gas chromatograph on an HP-1 column combined with a VG Masslab mass spectrometer. The water content in DMF was determined by means of a Metrohm, Herisau $737 \mathrm{KF}$ coulometer. Analytical electrochemical experiments were conducted in a standard electrochemical cell equipped with a working electrode made of gold or glassy carbon and having a diameter of $1 \mathrm{~mm}$, a reference electrode and a counter electrode made of platinum. The reference electrode consisted of a silver wire in tetrabutylammonium iodide/solvent or in some cases a FLEX-REF electrode from World Precision Instruments. The signals from a home-built potentiostat were recorded using a Nicolet $4094 \mathrm{c} / 4570$ digital oscilloscope and the equipment was controlled by means of a PC. The preparative experiments were carried out with a $200 \mathrm{~W}$ home-built three-electrode potentiostat in an $\mathrm{H}$-cell equipped with a platinum net or mercury pool as cathode, a silver wire in tetrabutylammonium iodide/ solvent as reference electrode and a carbon rod as anode.

Procedure. Analytical methods. In general, the cyclic voltammetric behaviour of all substrates was independent of the nature of the electrode material used (gold or glassy carbon). The scan rate, $v$, was varied typically between $0.05 \mathrm{~V} \mathrm{~s}^{-1}$ and $20 \mathrm{~V} \mathrm{~s}^{-1}$ and no electrochemically active impurities were detectable by cyclic voltammetry in the accessible potential window. The relevant standard potentials were measured (after electronic compensation of the ohmic drop) as the midpoint of the cathodic and anodic peaks in cyclic voltammetry against the ferrocenium/ferrocene redox pair $\left(\mathrm{Fc}^{+} / \mathrm{Fc}\right)$ with an estimated uncertainty of $\pm 5 \mathrm{mV}$. The standard potential of the latter couple was measured to 0.410 and $0.480 \mathrm{~V}$ vs. SCE in $\mathrm{CH}_{3} \mathrm{CN}$ and DMF, respectively. The supporting electrolyte was kept at a sufficiently high concentration $(0.1-0.3 \mathrm{M})$ to make migration effects negligible and at the same time lower the resistance in the solvents, in particular THF and $\mathrm{CH}_{2} \mathrm{Cl}_{2}$. The cleavage rate constants were determined as an average of at least five experiments. The program package BAS DigiSim 2.0 by Rudolph and Feldberg was used for all simulations unless otherwise noted. The diffusion coefficients of all species involved were assumed to be equal.
9-Chloroanthracene. The determination of the cleavage rate constant, $k_{\mathrm{cl}}$, of the radical anion of 9-chloroanthracene could be carried out in most solvents at any substrate concentration but in DMF and NMP a concentration of $10-20 \mathrm{mM}$ was preferable allowing the mechanism to be treated as DISP1. With $\mathrm{CH}_{2} \mathrm{Cl}_{2}$ as solvent a small contribution to the cyclic voltammetric behaviour from an electron transfer reaction between the radical anion of 9-chloroanthracene and the solvent cannot be excluded. The cleavage rate constant was determined by fitting the experimental results obtained by LSV at different scan rates to two sets of simulated curves obtained for the DISP1 mechanism as described in Ref. 59. The curves depicted the catalytic efficiency (defined as the ratio of the actual peak current, $I_{\mathrm{k}}$, and the one-electron peak current of the corresponding reversible process, $I_{\mathrm{r}}$ ) or the peak potential of the reduction wave, $E_{\mathrm{p}}$, as a function of $R T k_{\mathrm{cl}} / F \mathrm{v}$.

For NMP and DMF the substrate dependent competition between reactions (3) and (4) was observable and the hydrogen abstraction rate constant, $k_{\text {abs }}$, could be determined by comparing experimental cyclic voltammograms obtained at different substrate concentrations with theoretical curves. Reaction (3) was assumed to proceed by a rate constant at the diffusion limit $\left(5 \times 10^{9} \mathrm{M}^{-1} \mathrm{~s}^{-1}\right.$ and $10^{10} \mathrm{M}^{-1} \mathrm{~s}^{-1}$ for NMP and DMF, respectively, calculated from the Smoluchowski equation $)^{60}$ and the ratios $I_{\mathrm{k}} / I_{\mathrm{r}}$ of 1.3 and 1.5 obtained in the two solvents at the lowest scan rates and a substrate concentration of $1 \mathrm{mM}$ were used to obtain an initial measure of the competition ratio of reactions (5) and (6).

3-Nitrobenzyl chloride. The experiments with 3-nitrobenzyl chloride were carried out at high substrate concentrations of 10 and $20 \mathrm{mM}$ with freshly activated alumina added to the electrochemical cell in order to out-run the protonation reaction involving residual water. The supporting electrolyte was not involved in a protonation reaction either since variation of its concentration had no influence on the determination of the relevant rate constants. The cleavage rate constants obtained showed no dependence on the concentration of water added in small quantity $(\approx 5 \mathrm{mM})$. The latter point is rather important considering the stabilizing effect residual water (the concentration of which was determined to be ca. $3 \mathrm{mM}$ in DMF) might exert on radical anions with a localized charge. ${ }^{21}$ The cleavage and protonation rate constants, $k_{\mathrm{cl}}$ and $k_{\mathrm{pr}}$, were determined by fitting the experimental results obtained in LSV to working curves depicting $I_{\mathrm{k}} / I_{\mathrm{r}}$ or $E_{\mathrm{p}}$ as a function of $\lambda_{1}=R T k_{\mathrm{c} l} / F v$ for different values of $\lambda_{2}=c^{*} k_{\mathrm{pr}} / k_{\mathrm{cl}}$, where $c^{*}$ denotes the substrate concentration. In the simulation procedure the transfer coefficient was set equal to 0.5 and the heterogeneous charge transfer reaction was treated as a Nernstian process. For HMPA the scan rates employed were so high that a small effect due to quasi-reversible behaviour could be observed, resulting from the relatively low standard heterogeneous rate constant of $0.25 \mathrm{~cm} \mathrm{~s}^{-1}$. 
The reduction (11) of the generated 3-nitrotoluene was found to have some influence on the characteristics of the first wave and was therefore included in the simulations. The standard potential of 3-nitrotoluene was settled to a value $75 \mathrm{mV}$ lower than the standard potential of 3-nitrobenzyl chloride. Obviously, the standard potentials were solvent dependent but the average potential difference of $75 \mathrm{mV}$ measured by means of cyclic voltammetry showed only a small and negligible variation of a few millivolts among the different solvents. Reactions involving the radical anion of 3-nitrotoluene as reducing agent towards 3-nitrobenzyl chloride and 3-nitrobenzyl radical were also included in the simulations but their influence on the first reduction wave was small. A value of $10^{10} \mathrm{M}^{-1} \mathrm{~s}^{-1}$ was used for the diffusion-controlled rate constant of the homogeneous reduction process although the exact value is unimportant for the simulation procedure as long as it is high compared with the other rate constants.

3-Chloroacetophenone. The experiments with 3-chloroacetophenone were carried out at various substrate concentrations in the range $1-20 \mathrm{mM}$. Freshly activated alumina was added to the electrochemical cell to keep the content of residual water in each solvent as constant as possible from one experiment to another. The cleavage rate constant, $k_{\mathrm{cl}}$, and the dimerization rate constant, $2 k_{\mathrm{dim}}$, could be determined by fitting the experimental cyclic voltammograms (including the wave of the generated acetophenone) obtained at three different substrate concentrations and scan rates to digitally simulated curves. For the sake of completeness it should be noted that $k_{\text {dim }}$ rather than $2 k_{\mathrm{dim}}$ is the input parameter for the rate constant of a dimerization reaction in DigiSim 2.0. The rate constant of reaction (16) was settled to a high value compared with all other rate constants while the transfer coefficient was fixed at 0.5 and the standard heterogeneous rate constant at $0.1 \mathrm{~cm} \mathrm{~s}^{-1}$. The dimerization reaction of acetophenone radical anion as well as the cross reaction between the radical anions of 3-chloroacetophenone and acetophenone were included in the simulation procedure. In general, the second wave of acetophenone deviated somewhat from the theoretical curves as illustrated by Fig. 3 in which the dimerization reactions and the cross reaction were given the same rate constant of $k_{\mathrm{dim}}=10^{3} \mathrm{M}^{-1} \mathrm{~s}^{-1}$. The radical anion of acetophenone might therefore be involved in other reactions with intermediates or products formed during the scan. Still, the influence of these on the characteristics of the first wave seemed to be small and reproducible values of $k_{\mathrm{cl}}$ and $2 k_{\mathrm{dim}}$ could be obtained for the different scan rates and substrate concentrations employed. For NMP and DMSO the dimerization reaction was slow compared with the cleavage reaction and only an upper limit on $2 k_{\text {dim }}$ could be given. The experiments could not be carried out in $\mathrm{TBABF}_{4}-\mathrm{HMPA}$ because of background discharge and in $\mathrm{CH}_{2} \mathrm{Cl}_{2}$ the results were hampered by the presence of a fast electron transfer from the radical anion of 3-chloroacetophenone to the solvent.

Preparative reductions. Preparative reductions of 3-nitrobenzyl chloride and 3-chloroacetophenone were performed in deaerated $0.1 \mathrm{M} \mathrm{TBABF}_{4}-\mathrm{DMF}$ at platinum or mercury as working electrodes and at controlled potentials corresponding to the first wave in cyclic voltammetry $(-1.0$ and $-1.8 \mathrm{~V}$ vs. SCE, respectively). When the electrolysis was completed, water was added to the catholyte and the products were extracted three times with diethyl ether. The combined ether phases were subsequently washed three times with water. The product analysis was carried out using NMR, GC and MS.

3-Nitrobenzyl chloride. In the electrochemical reduction of $8 \mathrm{mM} 3$-nitrobenzyl chloride at a platinum net electrode, a drop in current was often noted after passage of about $1.2 \mathrm{~F}$. At higher substrate concentrations of $20 \mathrm{mM}$ the current drop occurred much earlier to the passage of $1 F$ and 3-nitrobenzyl chloride could be recovered in large amounts from the electrolysis solution. A likely explanation of this phenomenon is adsorption on and passivation of the platinum electrode surface by one of the generated intermediates or products. This was further substantiated by the observation that the electrolysis could be carried out with an electron consumption of about 1.4 when mercury was used as electrode material. Further reduction of products was difficult to avoid in these experiments. The isolated yield of products from the organic phase was in general rather low $(<30 \%)$ and thus underlines the high uncertainty associated with the determination of, in particular, the protonation rate constant in the analytical measurements. Presumably the low yield is due to formation of polymeric species on the long timescale of the preparative electrolysis. ${ }^{30}$ The main product was 3-nitrotoluene accompanied by varying amounts of 3-nitrobenzyl alcohol. In distilled or with well alumina-dried DMF, no alcohol could be detected at all but in untreated DMF or if small amounts of water were added to the solution prior to electrolysis, the amount of 3-nitrobenzyl alcohol increased, comprising $10-30 \%$ of the total yield. This could point to a protonation of 3-nitrobenzyl anion with water followed by an $\mathrm{S}_{\mathrm{N}} 2$ process between the thus formed hydroxide ion and 3-nitrobenzyl chloride. The isolation of 3-nitrotoluene as the only product in DMF under dry conditions combined with the finding of low electron consumption is strongly indicative of the protonation reaction (10). Also, in $\mathrm{CH}_{3} \mathrm{CN}^{30}$ and $\mathrm{CH}_{2} \mathrm{Cl}_{2}$ characterized by appreciably lower protonation rates, the product found was 3nitrotoluene. Interestingly, no products such as 1,2-bis(3nitrophenyl)ethane or 3,3'-dinitrostilbene, originating from nucleophilic behaviour of the two carbanions generated in (9) and (10) towards 3-nitrobenzyl chloride, could be detected in any of the experiments. In this respect, the 3-nitrobenzyl system behaves differently from the corresponding 2- and 4-nitro-substituted benzyl 
halides, the reduction of which results in 1,2-bis(2nitrophenyl)ethane and 1,2-bis(4-nitrophenyl)ethane, respectively. ${ }^{30}$ An attempt to trap a carbene intermediate, generated from the expulsion of chloride in the deprotonated 3-nitrobenzyl chloride, by cyclohexene was unsuccessful. If the electrolysis was carried out in the presence of four equivalents of deuteriated chloroform the charge consumption was close to $2 F$ with $\alpha$-deuterio3 -nitrotoluene now being the main product. This can hardly be explained by anything else but a protonation of 3-nitrobenzyl anion by $\mathrm{CDCl}_{3}$. The $\alpha$-deuterio-3nitrotoluene had the same retention time as 3-nitrotoluene in GC but it could be identified from the mass spectrum $(m / z=138)$.

3-Chloroacetophenone. Depending on the electrolysis conditions the charge consumption varied from 1.3 to $2 F$ and varying amounts of 2,3-bis(3-chlorophenyl)-2,3-butanediol and acetophenone could be isolated in high yields (ca. 80\%). At concentrations below $5 \mathrm{mM}$, acetophenone was typically the only product detected whereas substantial amounts of 2,3-bis(3-chlorophenyl)-2,3-butanediol could be isolated at higher substrate concentrations. In the presence of $100 \mathrm{mM}$ water the diol was the only product formed in a one-electron consumption process. This can be ascribed to the accelerating effect of water on the dimerization reaction. It is interesting to note that the $( \pm)$ to meso ratio of 2,3-bis(3-chlorophenyl)-2,3butanediol was found to be dependent on the nature of the solvent and the amount of water present. A similar trend has also been observed for other dimerization reactions. ${ }^{35,61}$ In well-dried DMF and $\mathrm{CH}_{3} \mathrm{CN}$ solutions the ratio was equal to 5.7 and 1.8 , respectively, whereas the corresponding numbers in the presence of $1 \%$ water were 5.5 and 5.7. The small influence of water in DMF may indicate relatively strong bonding of the water molecules to the solvent thus making them less available for a specific solvation of the radical anions.

The products were identified by NMR by comparing with the spectra of 2,3-diphenyl-2,3-butanediol reported previously $^{62}$ and the $( \pm)$ to meso ratio was determined from the signals of the methyl protons.

${ }^{1} \mathrm{H}$ NMR $\left(\mathrm{CDCl}_{3}\right)$ of 2,3-bis(3-chlorophenyl)-2,3-butanediol: $\delta 7.10-7.25(\mathrm{~m}, 12 \mathrm{H}), 7.00(\mathrm{~d}, 4 \mathrm{H}), 2.70(\mathrm{br} \mathrm{s}$, $2 \mathrm{H}$ from the $\mathrm{OH}$ groups), 2.15 (br s, $2 \mathrm{H}$ from the $\mathrm{OH}$ groups), $1.55(\mathrm{~s}, 6 \mathrm{H}), 1.50(\mathrm{~s}, 6 \mathrm{H})$. The signal at $\delta=$ 1.55 was attributed to the meso form and the one at 1.50 to the $( \pm)$ pair. The signals from the hydroxylic protons were as expected strongly concentration dependent.

\section{References}

1. Eberson, L. Electron Transfer Reactions in Organic Chemistry, Springer-Verlag, Heidelberg 1987.

2. Andrieux, C. P., Savéant, J.-M. and Zann, D. Nouv. J. Chim. 8 (1984) 107.

3. Andrieux, C. P., Le Gorande, A. and Savéant, J.-M. J. Am. Chem. Soc. 114 (1992) 6892.

4. Savéant, J.-M. Acc. Chem. Res. 26 (1993) 9.
5. Andrieux, C. P., Robert, M., Saeva, F. D. and Savéant, J.-M. J. Am. Chem. Soc. 116 (1994) 7864.

6. Neta, P. and Behar, D. J. Am. Chem. Soc. 102 (1980) 4798.

7. Neta, P. and Behar, D. J. Am. Chem. Soc. 103 (1981) 103.

8. Adcock, W., Andrieux, C. P., Clark, C. I., Neudeck, A., Savéant, J.-M. and Tardy, C. J. Am. Chem. Soc. 117 (1995) 8285.

9. Daasbjerg, K. J. Chem. Soc., Perkin Trans. 2 (1994) 1275.

10. Norris, R. K., Barker, S. D. and Neta, P. J. Am. Chem. Soc. 106 (1984) 3140.

11. Meot-Ner, M., Neta, P., Norris, R. K. and Wilson, K. J. Phys. Chem. 90 (1986) 168.

12. Andrieux, C. P., Differding, E., Robert, M. and Savéant, J.-M. J. Am. Chem. Soc. 115 (1993) 6592.

13. Masnovi, J. J. Am. Chem. Soc. 111 (1989) 908.

14. Kimura, N. and Takamuku, S. Bull. Chem. Soc. Jpn. 59 (1986) 3653 .

15. Kimura, N. and Takamuku, S. Radiat. Phys. Chem. 29 (1987) 179.

16. Kimura, N. and Takamuku, S. Bull. Chem. Soc. Jpn. 65 (1992) 1668.

17. Kimura, N. and Takamuku, S. J. Am. Chem. Soc. 117 (1995) 8023 .

18. Kimura, N. and Takamuku, S. Bull. Chem. Soc. Jpn. 64 (1991) 2433.

19. Wipf, D. O. and Wightmann, R. M. Anal. Chem. 62 (1990) 98.

20. Jaworski, J. S., Leszczynski, P. and Tykarski, J. J. Chem. Res. (S) (1995) 510.

21. Andrieux, C. P., Robert, M. and Savéant, J.-M. J. Am. Chem. Soc. 117 (1995) 9340.

22. Savéant, J.-M. J. Phys. Chem. 98 (1994) 3716.

23. Andrieux, C. P., Savéant, J.-M., Tallec, A., Tardivel, R. and Tardy, C. J. Am. Chem. Soc. 118 (1996) 9788.

24. Gores, G. J., Koeppe, C. E. and Bartak, D. E. J. Org. Chem. 44 (1979) 380.

25. M'Halla, F., Pinson, J. and Savéant, J.-M. J. Am. Chem. Soc. 102 (1980) 4120.

26. Pedersen, S. U., Lund, T., Daasbjerg, K., Pop, M., Fussing, I. and Lund, H. Acta Chem. Scand. 52 (1998) 657.

27. Occhialini, D., Kristensen, J. S., Daasbjerg, K. and Lund, H. Acta Chem. Scand. 46 (1992) 474.

28. Kjær, N. T. and Lund, H. Acta Chem. Scand. 49 (1995) 848.

29. Grimshaw, J., Langan, J. R. and Salmon, G. A. J. Chem. Soc., Faraday Trans. 90 (1994) 75.

30. Lawless, J. G., Bartak, D. E. and Hawley, M. D. J. Am. Chem. Soc. 91 (1969) 7121.

31. Bard, A. J. and Faulkner, L. R. Electrochemical Methods, Fundamentals and Applications, Wiley, New York, 1980.

32. Wipf, D. O. and Wightmann, R. M. J. Phys. Chem. 93 (1989) 4286.

33. Savéant, J.-M. and Tessier, D. J. Electroanal. Chem. 61 (1975) 251.

34. Baizer, M. M. In: Baizer, M. M. and Lund, H., Eds., Organic Electrochemistry, 3rd. ed., Marcel Dekker, New York 1991.

35. Fussing, I., Güllü, M., Hammerich, O., Hussain, A., Nielsen, M. F. and Utley, J. H. P. J. Chem. Soc., Perkin Trans. 2 (1996) 649.

36. Lamy, E., Nadjo, L. and Savéant, J.-M. J. Electroanal. Chem. 50 (1974) 141.

37. Krygowski, T. M., Lipsztajn, M. and Galus, Z. J. Electroanal. Chem. 42 (1973) 261.

38. Chauhan, B. G., Fawcett, W. R. and Lasia, A. J. Phys. Chem. 81 (1977) 1476.

39. Jaworski, J. S. J. Electroanal. Chem. 219 (1987) 209.

40. Fawcett, W. R., Opallo, M., Fedurco, M. and Lee, J. W. J. Am. Chem. Soc. 115 (1993) 196.

41. Dubois, D., Monninot, G., Kuntner, W., Jones, M. T. and Kadish, K. M. J. Phys. Chem. 96 (1992) 7137. 
42. Kitagawa, T., Layloff, T. and Adams, R. N. Anal. Chem. 36 (1964) 925

43. Swaan, M. and Parker, V. D. Acta Chem. Scand. Ser. B 38 (1984) 751.

44. Pcover, M. E. and Davies, J. D. J. Electroanal. Chem. 6 (1963) 46

45. Nicholson, R. S. and Shain, I. Anal. Chem. 36 (1964) 706.

46. Gambert, R. and Baumgärtel, H. J. Electroanal. Chem. 183 (1985) 315.

47. Petersen, R. A. and Evans, D. H. J. Electroanal. Chem. 222 (1987) 129.

48. Andreu, R., Calvente, J. J., Faweet, W. R. and Molero, M. J. Phys. Chem. 101 (1997) 2884.

49. Esin, O. and Marcov, B. Acta Physicochem. URSS 10 (1939) 353.

50. Mohilner, D. M. Electroanal. Chem. 1 (1966) 241.

51. Gutmann, V. The Donor-Acceptor Approach to Molecular Interactions, Plenum Press, New York 1978 and references cited therein.

52. Kamlet, M. J., Abboud, J. L. M. and Taft, R. W. Prog. Phys. Org. Chem. 13 (1980) 485.
53. Marcus, Y., Kamlet, M. J. and Taft, R. W. J. Phys. Chem. 92 (1988) 3613.

54. Reichardt, C. Solvents and Solvent Effects in Organic Chemistry, 2nd ed., Weinheim, Basel 1988.

55. Reichardt, C. Chem. Rev. 94 (1994) 2319.

56. Fawcett, W. R. J. Phys. Chem. 97 (1993) 9540.

57. Izutsu, K. Acid Base Dissociation Constants in Dipolar Aprotic Solvents, Chemical Data Series No. 35, Blackwell, Oxford 1990.

58. Nielsen, M. F., Eggert, H. and Hammerich, O. Acta Chem. Scand. 45 (1991) 292.

59. Nadjo, L. and Savéant, J.-M. J. Electroanal. Chem. 48 (1973) 113.

60. Grampp, G. and Jaernicke, W. Ber. Bunsenges. Phys. Chem. 95 (1991) 904.

61. Bewick, A. and Brown, D. J. J. Chem. Soc., Perkin Trans. 2 (1977) 99.

62. Agahigian, H., Moraveck, J. F. and Gauthier, H. Can. J. Chem. 4 l (1963) 194

Received February 5, 1998. 